\title{
Adsorption of a Synthetic Heparinoid Polyelectrolyte on an lon-Exchanging Surface
}

\author{
PETER E. FROEHLING AND ADRIAAN BANTJES \\ Laboratory for Macromolecular Chemistry, Twente University of Technology, Enschede, The Netherlands \\ AND \\ Z. KOLAR \\ Interuniversity Reactor Institute, Delft, The Netherlands
}

Received September 29, 1976; accepted January 13, 1977

\begin{abstract}
The adsorption of a synthetic heparinoid polyelectrolyte on poly (vinylchloride) previously treated with tridodecylmethylammonium chloride (TDMAC) was studied using radiotracer techniques to provide a more quantitative picture of antithrombogenic surface coatings. ${ }^{125}$ I.labeled polyelectrolyte was used for overall adsorption measurements. Experiments with ${ }^{36} \mathrm{Cl}$-labeled TDMAC yielded information on actually adsorbed polyelectrolyte segments in good agreement with existing theory. A large excess of free dangling segments was found. In the presence of $\mathrm{NaCl}$ the total adsorption. was diminished, although no desorption occurred on treatment of adsorbates with $0.15 \mathrm{M} \mathrm{NaCl}$ or blood plasma.
\end{abstract}

\section{INTRODUCTION}

The polyelectrolyte anticoagulant heparin constitutes a basis for a variety of nonthrombogenic surface coatings for medical appliances in which blood-compatible materials are required (1). In recent publications from this laboratory the synthesis (2) and anticoagulant properties $(3,4)$ of a heparin-like polyelectrolyte $\mathrm{P}$ have been reported:

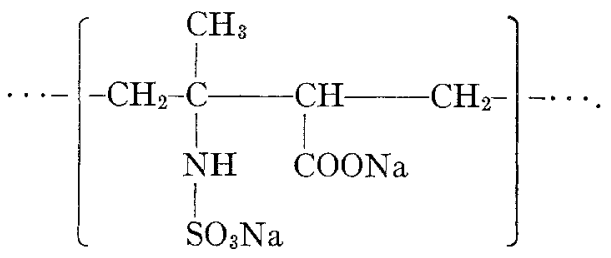

The application of $\mathrm{P}$ analogously to heparin in the preparation of antithrombogenic surfaces is under current investigation.

Covalent and ionic processes to bind heparin to surfaces have been described (1). In ionic binding extensive use has been made of the water-insoluble quaternary ammonium salt tridodecylmethylammonium chloride (TDMAC), which can be adsorbed from organic solvents on the material to be treated. The anion exchanging capacity thus obtained can be used in a second step to adsorb heparin from aqueous solution. Another ionic binding process uses the TDMA salt of heparin which is prepared separately and brought in one step on the material to be treated. Froehling et al. have reported on the preparation and blood-contact properties of coatings of the TDMA derivative of $\mathrm{P}(5)$.

The uptake of TDMAC by poly(vinylchloride) from several solvent systems has been described (6). It appears that the TDMAC actually dissolves into the swollen polymer, thus leaving only a small ion exchange capacity on the materials' surface. In this publication we report on the adsorption of $\mathrm{P}$ by TDMACtreated PVC powder, using radiotracer techniques. The results will be discussed in the light of current theories on polyelectrolyte 
adsorption in relation to the applicability of antithrombogenic coatings based on $\mathrm{P}$ and on heparin.

\section{MATERIALS AND METHODS}

Polyelectrolyte $\mathrm{P}$ was prepared according to Van der Does (2) and further purified by dialysis against distilled water and reprecipitation in ethanol. Elementary analysis gave $\mathrm{Na}=12.1 \%$ by weight, indicating an equivalent weight for ion exchange of 190.1. The number-average molecular weight of $\mathrm{P}$ was 750,000 (van der Does, personal communication). The ${ }^{125}$ I-labeled polyelectrolyte was prepared from purified material by iodination with carrier-free ${ }^{125} \mathrm{I}$ using a modification of the method described by Greenwood (7). Thirty microliters of a $0.5 \%$ aqueous solution of $\mathrm{P}$ were mixed with $20 \mu \mathrm{l}$ of a $0.05 \mathrm{M}$ phosphate buffer ( $\mathrm{pH} 7.5)$ and $10 \mu \mathrm{l}$ of an aqueous carrier-free $\mathrm{Na}^{125}$ I solution (The Radiochemical Centre, Amersham). Twenty microliters of a $4 \%$ chloramine-T solution in the same phosphate buffer were added, followed after $1 \mathrm{~min}$ by $0.3 \mathrm{ml}$ of a $2.5 \%$ aqueous solution of $\mathrm{Na}_{2} \mathrm{~S}_{2} \mathrm{O}_{5}$ and $0.3 \mathrm{ml}$ of a $1 \% \mathrm{KI}$ solution. The mixture was dialyzed for $2 \times 7$ and $1 \times 16 \mathrm{hr}$ against 1 liter of distilled water. The yield of the labeling procedure (polyelectrolyte-bound ${ }^{125} \mathrm{I}$ ) was $60 \%$ as determined by radioactivity measurements. From dialysis (and electrophoresis) the labeled polyelectrolyte proved to be identical to the starting material. Presumably the iodine is added to a remainder of double bonds present in $\mathrm{P}$, originating from the starting material of the $\mathrm{P}$ synthesis, polyisoprene (2).

A $0.1 \%$ stock solution of $\mathrm{P}$ was made by transferring the dialyzed ${ }^{125}$ I-polyelectrolyte to a $10 \mathrm{ml}$ volumetric flask containing $9.85 \mathrm{mg}$ of unlabeled $\mathrm{P}$ and $2 \mathrm{mg}$ of sodium azide (a bacteriostatic agent), and filling up with water. The preparation of TDMAC-loaded PVC powders (specific area $1 \mathrm{~m}^{2} / \mathrm{g}$ ) was carried out as described before (6). Adsorption experiments were performed by shaking $1 \mathrm{~g}$ of TDMAC-loaded PVC with $4 \mathrm{ml}$ of poly- electrolyte solution, made up with the stock solution and appropriate quantities of unlabeled $\mathrm{P}$, water and in some cases $\mathrm{NaCl}$. Adsorption equilibrium was generally attained after $40 \mathrm{hr}$ at about $20^{\circ} \mathrm{C}$.

One-milliliter samples of the initial solution and of the liquid in equilibrium with the solid were removed for radioactivity measurements. A $3 \times 3$ in. $\mathrm{NaI}(\mathrm{Tl})$ well-type scintillation detector coupled to a Tracor Northern Econ II multichannel analyzer was used for this purpose. The amount of adsorbed polyelectrolyte per gram of adsorbent $(w)$ was calculated as $w=\left(c_{\mathrm{i}}-c_{\mathrm{f}}\right) V / m$, where $c_{\mathrm{i}}$ and $c_{\mathrm{f}}$ are the initial and final concentrations of polyelectrolyte, $V=$ total volume, and $m=$ weight of adsorbent in grams.

The final polyelectrolyte concentration was calculated from $c_{\mathrm{f}}=c_{\mathrm{i}} R_{\mathrm{f}} / R_{\mathrm{i}}$, where $R_{\mathrm{f}}$ and $R_{\mathrm{i}}$ are the counting rates of equilibrium and initial solution.

Desorption of $\mathrm{P}$ from the TDMAC-polyelectrolyte treated surface was attempted by using saline solution and bovine plasma. For these experiments the powders were filtered off, washed rapidly with water, and dried. Four hundred milligrams of powder and $4 \mathrm{ml}$ of $0.15 \mathrm{M} \mathrm{NaCl}$ or citrated bovine plasma were shaken for $24 \mathrm{hr}$ at about $20^{\circ} \mathrm{C}$, and the ${ }^{125} \mathrm{I}$ activity of the solutions was determined by counting. The release of chloride ions due to ion-exchange adsorption of $\mathrm{P}$ was measured in experiments in which TDMAC-loaded PVC powders with ${ }^{36} \mathrm{Cl}$-labeled surface chloride ions, the preparation of which is described elsewhere (6), were contacted with solutions of unlabeled P. Chloride concentrations were measured by liquid scintillation counting of ${ }^{36} \mathrm{Cl}$ in a Packard TriCarb Model 3320 Liquid Scintillation Spectrometer, using $10 \mathrm{ml}$ of Packard "Instagel" scintillation medium and $0.1 \mathrm{ml}$ of liquid sample for each measurement.

\section{RESULTS}

Adsorption isotherms of $\mathrm{P}$ on three different TDMAC-PVC powders are given in Fig. 1. Because of the high viscosity of concentrated 
$P$ solutions measurements in the concentration region yielding a possible plateau value in the isotherm could not be carried out.

On untreated PVC no adsorption of $\mathrm{P}$ was found. Added $\mathrm{NaCl}$ greatly reduced the adsorption of $P$, as is shown in Fig. 2 for one TDMAC load. With the other loads a similar pattern was observed. From desorption experiments (see also Table I) it appeared that in the presence of $0.15 \mathrm{M} \mathrm{NaCl}$ or bovine plasma no labeled polyelectrolyte was eluted from the adsorbent.

The results of adsorption experiments with unlabeled $\mathrm{P}$ on the ${ }^{36} \mathrm{Cl}$-labeled TDMACloaded PVC are summarized in Table I. The number of actually adsorbed polyelectrolyte segments per molecule was calculated from the number of chloride ions released by ion exchange and from the amount of adsorbed $P$, obtained from the experiments with labeled polyelectrolyte under identical conditions.

\section{DISCUSSION}

Several models for the adsorption of polyelectrolytes by ion exchangers have been presented in the literature. However, little experimental support for these models has been presented up to now.

Frisch and Stillinger (8) calculated the electric work to be done in bringing a charged

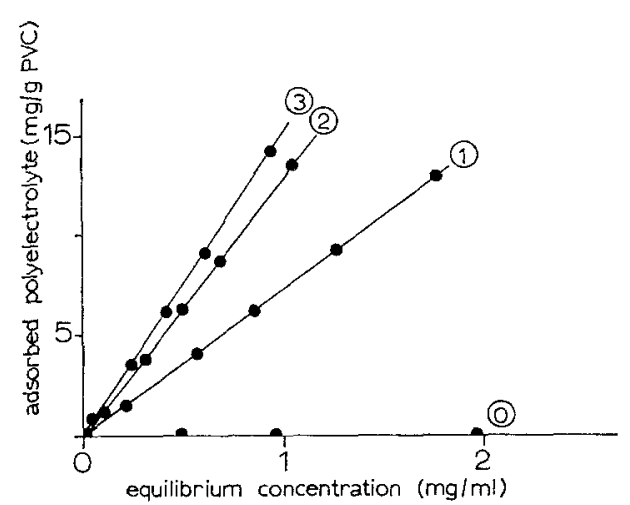

FIG. 1. Adsorption isotherms $\left(20^{\circ} \mathrm{C}\right)$ of $\mathrm{P}$ on TDMAC-treated PVC: 0 , no TDMAC; $1,0.0515 \mu \mathrm{eq}$ TDMAC/g PVC; $2,0.2167 \mu \mathrm{eq} / \mathrm{g} ; 3,0.3051 \mu \mathrm{eq} / \mathrm{g}$.
TABLE I

Determination of the Number of Adsorbed Segments per Polyelectrolyte Molecule

\begin{tabular}{|c|c|c|c|}
\hline $\begin{array}{c}\text { TDMAC/PVC } \\
\text { ion-exchange } \\
\text { capacity } \\
(\mu \mathrm{eq} / \mathrm{g})\end{array}$ & $\begin{array}{l}\text { Adsorbed } \\
\text { polyelec- } \\
\text { trolyte } \\
(\mu \mathrm{eq} / \mathrm{g})^{\alpha}\end{array}$ & $\begin{array}{l}\text { Released } \\
\text { chloride } \\
(\mu \mathrm{eq} / \mathrm{g})\end{array}$ & $\begin{array}{l}\text { Number of } \\
\text { adsorbed } \\
\text { segments per } \\
\text { molecule }\end{array}$ \\
\hline \multirow[t]{5}{*}{0.0515} & $3.9^{\circ}$ & 0.034 & 34.4 \\
\hline & 14.1 & 0.035 & 9.8 \\
\hline & 24.0 & 0.036 & 5.9 \\
\hline & 46.3 & 0.039 & 3.3 \\
\hline & $62.7^{\circ}$ & 0.039 & 2.5 \\
\hline \multirow[t]{5}{*}{0.2167} & 4.9 & 0.096 & 77.4 \\
\hline & 14.4 & 0.096 & 26.3 \\
\hline & 28.1 & 0.095 & 13.4 \\
\hline & 36.4 & 0.096 & 10.4 \\
\hline & 68.2 & 0.094 & 5.4 \\
\hline \multirow[t]{5}{*}{0.3051} & $3.5^{c}$ & 0.156 & 176.0 \\
\hline & 12.1 & 0.155 & 50.6 \\
\hline & 28.6 & 0.153 & 21.1 \\
\hline & 43.2 & 0.153 & 14.0 \\
\hline & $78.4^{\mathrm{c}}$ & 0.153 & 7.7 \\
\hline
\end{tabular}

${ }^{a}$ From adsorption experiments with labeled polyelectrolyte.

${ }^{b}$ Assumed molecular weight of $\mathrm{P}: 750,000$.

- Samples of this composition used for desorption experiments.

rigid rod (model for a polyelectrolyte molecule in salt-free solution) to a charged surface. Because of mathematical complications only qualitative conclusions can be drawn from their work. It appears that a large fraction of polymer segments is bound to the adsorbent.

Semenza (9) investigated the ion exchange chromatography of polyelectrolytes using an oversimplified model based on elementary mass action laws, neglecting all specific polymer effects. The adsorption behavior of lysine oligomers $(n<15)$ on carboxymethyl cellulose could, however, be reasonably described by this model (10).

An extensive treatment of the problem is given by Hesselink (11). He uses the HermansOverbeek approach for the electrostatic interactions near the charged surface, and a statistical mechanical solution as formulated by Hoeve (12) for the configurational aspects of the adsorbed polymer molecule. Hesselink concludes that the number of actually ad- 


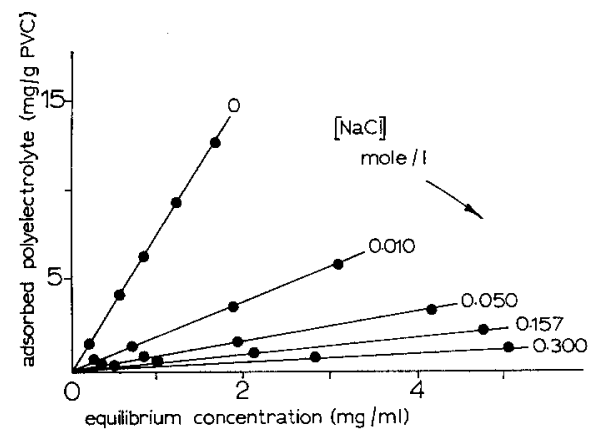

Fig. 2. Adsorption isotherms $\left(20^{\circ} \mathrm{C}\right)$ of $\mathrm{P}$ on TDMAC-treated PVC $(0.0515 \mu \mathrm{eq} / \mathrm{g})$ in the presence of $\mathrm{NaCl}$.

sorbed polymer segments ("trains" in the nomenclature of Silberberg (13)) rapidly reaches a saturation value as the polyelectrolyte concentration rises; the number of free dangling chain fragments ("loops" and "tails") greatly increases near the saturation value of the number of trains so that the attachment of the adsorbed layer decreases.

These data are in good agreement with our experimental findings (Table I) and with those of Ueda (14) for the ion exchange adsorption of a cationic polyelectrolyte on bentonite. The effect of added $\mathrm{NaCl}$ (Fig. 2) contrasts to the results of several authors, who find an increased adsorption of polyelectrolyte in the presence of added salt (14-17). Generally this increase in adsorption is interpreted as being caused by the well-known coiling of originally rigid polyelectrolyte molecules due to shielding of the charges by small ions. It is assumed that a larger number of coiled-up molecules can reach the surface, resulting in an increased amount of adsorbed molecules. The cause of the reverse effect in our system is yet to be elucidated. Ueda (14) found that in $\mathrm{NaCl}$ solution a smaller number of segments per molecule was attached to the ion exchanger than in salt-free solution. Under our experimental conditions measurement of this effect was not possible.

The adsorption of $P$ is irreversible, as is the case with the system studied by Ueda (14). Possibly the relatively thick layer of nonadsorbed segments prevents the approach of small ions which could cause desorption. As in some cases the number of ionically bound segments is quite small (2.5 per molecule), it must be assumed that hydrophobic bonding, e.g., through unsubstituted isoprene units of $\mathrm{P}(2)$, must also play a role in the adsorption. The irreversibility, and the analog inertness against plasma, are important in view of the applicability of the surface coatings obtained by the adsorption of $\mathrm{P}$ as nonthrombogenic materials. Generally, heparinized coatings possess no permanent stability against plasma or salt solutions $(18,19)$. This may be caused by the much smaller size of the heparin molecule compared to $P$, resulting in a smaller number of adsorption sites per molecule. Moreover, the heparin molecule possesses no sites for possible hydrophobic bonding, which might contribute to the resistance against desorption. A detailed picture of the structure of heparinized coatings, as given above for $\mathrm{P}$ adsorbates, is, however, lacking at this moment. In heparinized coatings, and also in coatings from $\mathrm{P}$, the excess of anionic sites gives the surface a negative charge. Sawyer (20) has postulated that a negative $\zeta$-potential generally renders a surface nonthrombogenic. It is also possible that the surface-bound anticoagulant molecules can interact specifically with the coagulation mechanism through the large fraction of nonadsorbed segments in the same way as when dissolved in the blood plasma (21), thus causing the nonthrombogenicity of the coating.

On the blood-contact properties of the above described coatings of $\mathrm{P}$ and on their specific interactions with the coagulation mechanism we will report elsewhere (Froehling, in preparation).

\section{ACKNOWLEDGMENTS}

The cooperation of Dr. C. J. A. van den Hamer and Mr. E. Sedlick in the preparation of labeled polyelectrolyte, and the valuable comments of Dr. A. van der Scheer are gratefully acknowledged.

\section{REFERENCES}

1. FAls, R. D., Leininger, R. I., GRODE, G., AND Crowler, J., in "Heparin: Structure, Function 
and Clinical Implications" (R. A. Bradshaw and S. Wessler, Eds.), p. 365. Plenum, New York, 1975.

2. Van der Does, L., Hofman, J., and Van Utteren, T. E. C., Polym. Lelt. Ed. 11, 169 (1973).

3. Beugeling T., Van der Does, L., Bantjes, A., and Sederel, W. L., $J$. Biomed. Mat. Res. 8, 375 (1974).

4. Bevget.jng, T., Van der Does, L., Rejda, B.V., and BantJes, A., in "Biocompatibility of Implant Materials" (D. Williams, Ed.), p. 187. Sector, London, 1976.

5. Froehling, P. E., Beugeling, T., Van der Does, L., Feyen, J., And Bantjes, A., J. Biomed. Mat. Res., to appear.

6. Froehldng, P. E., Koenhen, D. M., Smolders, C. A., and Bantjes, A., J. Appl. Polym. Sci., to appear.

7. Greenwood, F. C., Hunter, W. M., ANd Glover, J. S., Biochem. J. 89, 114 (1963).

8. Frisch, H. L., ANd StIllinger, F. H., J. Phys. Chem. 66, 823 (1962).
9. SeMEnza, G., J. Chromatogr. 18, 359 (1965).

10. Suith, M. A., Stahmann, M. A., and Semenza, G., J. Chromalogr. 18, 366 (1965).

11. Hesselink, F. T., J. Electroanal. Chem. 37, 317 (1972).

12. Hoeve, C. A. J., DiMarzio, E. A., And Peyser, P., $J$. Chem. Phys. 42, 2558 (1965).

13. Silberberg, A., Pure Appl. Chem. 26, 583 (1971).

14. Ueda, T., and Harada, S., J. Appl. Polym. Sci. 12, 2395 (1965)

15. Lindoquist, G. M., And Stratton, R. A., J. Colloid Interface Sci. 55, 45 (1976).

16. Miller, I. R., J. Polym. Sci. 16, 1433 (1967).

17. Peyser, P., And Ullman, R., J. Polym. Sci. A 3, $3165(1965)$.

18. Tanzawa, H., Trans. Amer. Soc. Artif. Intern. Organs 19, 188 (1973).

19. Ehrlich, J., Polym. Eng. Sci. 15, 281 (1975).

20. Sawyer, P. N., Suckling, E. E., AND Wesolowski, S. A., Amer. J. Physiol. 198, 1006 (1960).

21. Damus, P. S., Hicks, M., and Rosenberg, R. D., Nature (London) 246, 355 (1973). 